\title{
Saprophytic Activity and Sporulation of Cryphonectria parasitica on Dead Chestnut Wood in Forests with Naturally Established Hypovirulence
}

\author{
S. Prospero, M. Conedera, U. Heiniger, and D. Rigling
}

Swiss Federal Institute for Forest, Snow and Landscape Research WSL, 8903 Birmensdorf, Switzerland. Current address of S. Prospero: INRA, UMR BIOGECO, Equipe de Pathologie Forestière, 33883 Villenave d'Ornon, France. Accepted for publication 29 June 2006.

\begin{abstract}
Prospero, S., Conedera, M., Heiniger, U., and Rigling, D. 2006. Saprophytic activity and sporulation of Cryphonectria parasitica on dead chestnut wood in forests with naturally established hypovirulence. Phytopathology 96:1337-1344.

Sustainable biological control of the chestnut blight fungus Cryphonectria parasitica with hypovirulence depends on the production and dissemination of hypovirus-infected propagules of the pathogen. We investigated the ability of $C$. parasitica to sporulate and produce hypovirus-infected spores on recently dead chestnut wood in coppice stands in southern Switzerland where hypovirulence has been naturally established. The number and type (active, inactive, or none) of cankers was assessed on experimentally cut and stacked stems, firewood stacks, and natural dead wood. Hypovirus-free and hypovirus-infected strains readily survived for more than 1 year in the chestnut blight cankers of the stacked
\end{abstract}

ABSTRACT stems. Sporulation of $C$. parasitica was observed on the surface of preexisting inactive and active cankers, as well as on newly colonized bark areas and was significantly more abundant than on comparable cankers on living stems. On all types of dead wood, we observed more stromata with perithecia than with pycnidia; however, a large proportion of the stromata was not differentiated. All perithecia examined yielded only hypovirus-free ascospores. The incidence of pycnidia that produced hypovirus-infected conidia ranged from $5 \%$ on natural dead wood to $41 \%$ on the experimental stacks. The mean virus transmission rate into conidia was $69 \%$. Our study demonstrates a considerable saprophytic activity of C. parasitica on recently dead chestnut wood and supports the hypothesis of a role of this saprophytic phase in the epidemiology of hypovirulence.

Additional keywords: Castanea sativa, Cryphonectria hypovirus, CHV-1, reproductive biology, sexual and asexual reproduction.
Cryphonectria parasitica (Murr.) Barr, the causal agent of chestnut blight encountered susceptible chestnut (Castanea sp.) species following its introduction into North America and Europe (2). In contrast to North America, where C. parasitica virtually eliminated the American chestnut (Castanea dentata (Marsh.) Borkh.) in its natural range, in Europe the severity of the disease on the European chestnut (Castanea sativa Mill.) gradually has decreased, resulting in the recovery of chestnut populations. This recovery has been attributed to the occurrence of hypovirulence, a viral disease in the pathogen population (for reviews see $2,16,21,24,28,30,33,39,46)$. Hypovirulence in $C$. parasitica is caused by double-stranded (ds) RNA viruses of the family Hypoviridae (25), which reduce virulence and sporulation capacity of infected fungal strains $(34,37)$. In Europe to date, only Cryphonectria hypovirus 1 (CHV-1) has been found $(1,20,43)$.

Hypoviruses can be transmitted from infected to noninfected C. parasitica strains via hyphal anastomosis providing the basis for biological control of the disease $(4,47)$. Transmission of the hypovirus among fungal strains is limited by a vegetative incompatibility (vic) system involving at least six vic loci $(13,14)$. The hypovirus also can be transmitted into asexual conidia $(34,41)$, which presumably play an important role for dissemination. By contrast, hypovirus-infected sexual ascospores have never been observed $(3,10)$. Consequently, sexual reproduction in $C$. parasitica is a major obstacle to the dissemination of the hypovirus since it only contributes to the spread of the virulent form of the

Corresponding author: D. Rigling; E-mail address: daniel.rigling @wsl.ch

DOI: 10.1094/PHYTO-96-1337

() 2006 The American Phytopathological Society pathogen. Moreover, sexual reproduction of $C$. parasitica has the potential to maintain or increase the diversity of vegetative compatibility (vc) types through recombination of vic genes (29). In Europe, low ve type diversity in subpopulations of $C$. parasitica is thought to be an important factor in the success of hypovirulence $(5,7,15,38)$. Milgroom and Cortesi (29) showed that this low diversity is due to a combination of low vic-allele diversity and limited recombination.

Chestnut blight is successfully controlled by hypovirulence in many locations in Europe, either naturally or after biocontrol treatments $(24,30,38)$. How the hypovirus spreads, however, has not been fully explained (26). Chestnut forests where hypovirulence is widespread are characterized by high disease incidence but low disease severity leaving most chestnut trees with one or more inactive, mostly superficial cankers $(7,30,38)$. Because sporulation of the fungus is rare or absent on inactive cankers (34, D. Rigling and U. Heiniger, unpublished data), their role for the spread of CHV-1 is uncertain. In contrast, abundant sporulation has been noticed on the bark of dead chestnut wood, which apparently has been saprophytically colonized by the fungus (12, 35 ). The saprophytic growth of $C$. parasitica might play a role in the epidemiology of hypovirulence $(16,31,46)$, however, no comprehensive information is available on the activity of the pathogen on dead wood either in Europe or North America. The few studies from the United States mainly have focused on the saprophytic growth of $C$. parasitica on tree species other than chestnut (6).

This study addresses the saprophytic role of $C$. parasitica in the epidemiology of the chestnut blight and particularly in the dissemination of hypovirus. We investigated the growth and sporulation of $C$. parasitica on dead chestnut stems that were experimentally cut and stacked in the forest. For comparison, sporula- 
tion of $C$. parasitica was analyzed on stems that died naturally and stems that were cut and stacked by forest owners for the use as firewood. We specifically considered (i) the extent of growth and sporulation of $C$. parasitica on dead chestnut stems compared to cankers on living trees; (ii) the frequency of sexual and asexual reproduction on dead chestnut wood; and (iii) the incidence of hypovirus-infected spores.

\section{MATERIALS AND METHODS}

Study sites. The study was conducted in the chestnut area of Canton Ticino in southern Switzerland, where chestnut blight was first observed in 1948 and natural hypovirulence is presently widespread $(7,11,24)$. Chestnut forests in Ticino cover about 30,000 ha forming an almost continuous belt at elevations between 200 and $1,000 \mathrm{~m}$. The region has a mild-temperate climate, with a mean annual precipitation of 1,600 to $1,700 \mathrm{~mm}$ and a mean annual temperature of about $12^{\circ} \mathrm{C}(44)$. About half of the precipitation occurs during the summer (June to September). The 11 study sites that we selected (Fig. 1) were represented by pure, extensively managed chestnut coppice stands aged from 5 to 50 years. With regard to chestnut blight incidence and severity, these sites can be considered representative of the situation in southern Switzerland, i.e., high incidence but low severity of the disease (7).

Experimental stacks. Dead wood with and without $C$. parasitica cankers was produced in five chestnut coppice stands (Fig. 1). In March 1996, in each site we selected 10 healthy sprouts (i.e., without cankers), 10 sprouts with an inactive canker, and 10 live sprouts with an active canker. Sprouts had a mean diameter at breast height of $8.1 \pm 2.6 \mathrm{~cm}$. Morphology of the cankers was

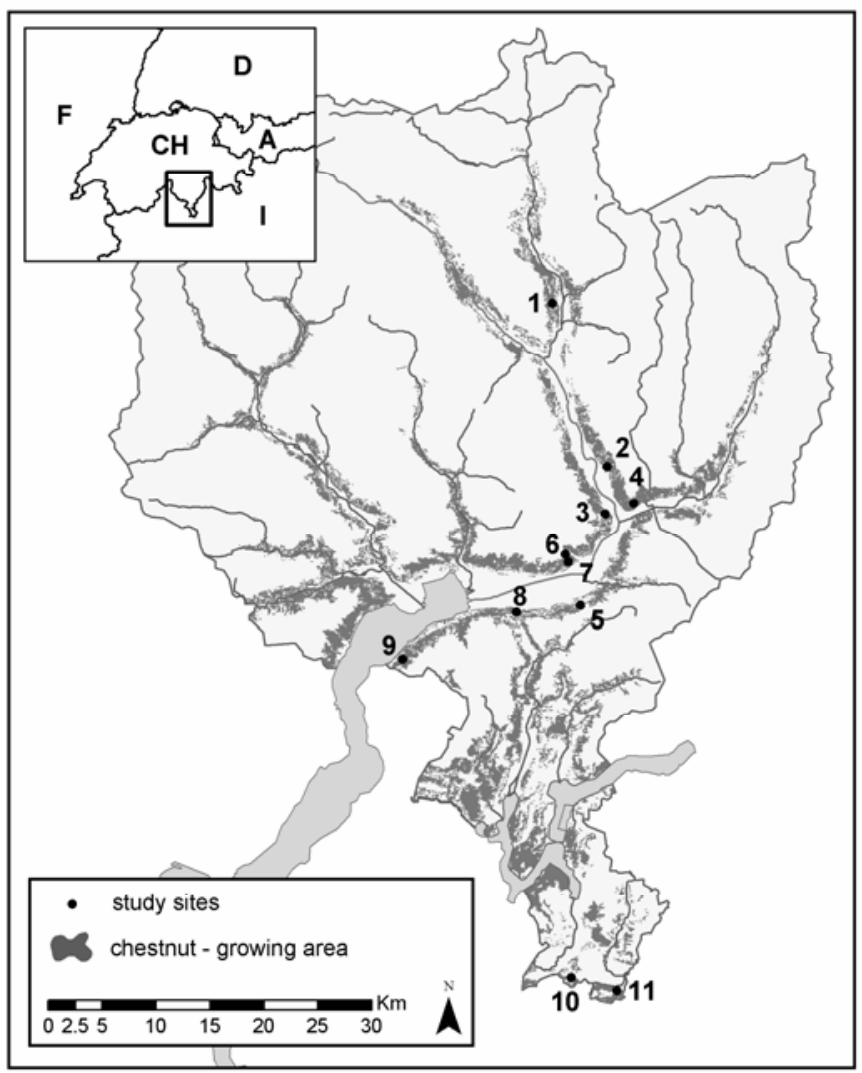

Fig. 1. Chestnut area of Canton Ticino and study sites. 1, Ludiano $(410 \mathrm{~m}$ above sea level); 2, Claro (680 m); 3, Gnosca (320 m); 4, Lumino (370 m); 5, Copera $(570 \mathrm{~m}) ; 6$, Sementina $1(680 \mathrm{~m}) ; 7$, Sementina 2, (440 m); 8, Contone $(205 \mathrm{~m}) ;$ 9, Gerra $(540 \mathrm{~m})$; 10, Novazzano $(480 \mathrm{~m}) ; 11$, Pedrinate $(500 \mathrm{~m})$. Experimental stacks and natural dead wood, sites 1 to 5; firewood stacks, sites 6 to 11 . used to differentiate canker types. A canker was considered inactive when the infection appeared superficial (i.e., restricted to the outer layer of the bark) sometimes calloused and no signs of an active expansion were visible (i.e., quiescent margins without reddish color). Inactive cankers are known colloquially as healed cankers. By contrast, an active canker was characterized by a reddish necrosis (sunken or superficial) with expanding margins. Representative pictures of the two canker types are shown in Heiniger and Rigling (24). Five sprouts in each category were cut and five stem segments (i.e., one per sprout) of $1 \mathrm{~m}$ length (including the canker where present) were placed side by side across two healthy chestnut stems that were laid on the ground (i.e., cut stem segments were not in contact with the ground). The other 15 living sprouts (five in each category) were marked and used as living controls.

The length of the cankers or bark areas colonized was used to quantify growth of $C$. parasitica on stacked and on living stems. On the stacked stems, the presence of $C$. parasitica stromata and associated orange- to red-brown bark discoloration was used to delineate margins of colonization. All cut and live, standing stems were visually checked for the presence of stromata produced by C. parasitica. The abundance of the stromata (sporulation) was estimated using the following scale: $0=$ absent, $1=$ scarce, $2=$ several, and $3=$ abundant. Bark samples ( 2 to $5 \mathrm{~cm}^{2}$ in area) were removed with a knife from bark areas showing fresh sporulation and brought to the laboratory for further analysis. For each collected bark sample, we noted whether it was taken from a preexisting canker or from newly colonized bark areas.

Cankers as well as healthy stem sections were systematically sampled by removing five bark plugs using a cork borer $(5 \mathrm{~mm}$ in diameter). In the cankers, one bark plug was removed from the center and four from the margin. In the healthy stems, three bark plugs were removed from one side of the stem (i.e., one at each end and one in the center) and two from the opposite site. The holes produced by the cork borer were closed with mastic (LacBalsam, Scheidler GmbH, Minden, Germany) to avoid unintentional infections.

Canker measurements, assessment of stromata production, and sampling initially were conducted in March 1996 (beginning of the experiment) and then repeated in November 1996 (8 months later) and April 1997 (13 months later). In the second and third sampling, bark plugs from the preexisting cankers and from the healthy stem sections were taken from the March 1996 margins at a distance of approximately $2 \mathrm{~cm}$ from the holes produced by the first sampling.

Natural dead wood. In April 1997, at the five sites with experimental stacks, we collected one bark sample with stromata of $C$. parasitica from each of 20 (if available) standing or fallen chestnut stems that had died because of competition or other abiotic factors.

Firewood stacks. During the winter 1999/2000, at six sites (Fig. 1) chestnut trees were cut by the forest owners for the production of firewood and stacked at the edge of the stands. Traditionally, sprouts are cut into segments and stacked uncovered in the forests for 2 to 3 years, allowing rainfall to wash out the tannins. The individual stacks were composed of 50 to 500 stems and had a volume ranging from 3 to $60 \mathrm{~m}^{3}$. The mean diameter of the stacked stems varied between 9 and $28 \mathrm{~cm}$. In March 2001, we collected one bark sample with stromata of $C$. parasitica from each of 10 different stems in each stack.

Isolation of $\boldsymbol{C}$. parasitica and characterization of stromata. To isolate $C$. parasitica, the bark plugs were surface-sterilized and placed on tannic acid malt agar as described previously (27). To collect conidia, the bark samples with stromata were sprayed for 1 to $2 \mathrm{~s}$ with sterile distilled water and placed in a petri plate (diameter $5.5 \mathrm{~cm}$ ) containing a filter paper moistened with $1 \mathrm{ml}$ of sterile distilled water. The plates were incubated at room temperature under daylight for $4 \mathrm{~h}$ to promote the release of the conidial 
mass (sometimes as spore tendrils) from the mature pycnidia. Thereafter, each individual stroma was assessed under a dissecting microscope for the presence of perithecia, pycnidia, or nondifferentiated stromatal tissue. Perithecia were identified by the presence of their necks protruding from the surface of the yellowish or orange stroma or by their ostioles visible as black raised dots on the surface of the stroma. Stromata were regularly dissected to confirm the presence of perithecia, particularly when perithecial necks were not clearly visible. Pycnidia were identified by the presence of exuding masses of conidia. If neither perithecia nor pycnidia could be identified, the stromatal tissue was considered nondifferentiated. The density of stromata on each bark sample was calculated by dividing the total number of stromata by the area of the bark sample. In order to determine the hypovirus infection status of individual stromata, a small portion of stromatal tissue was transferred onto tannic acid malt agar (36) and the resulting colony evaluated morphologically as described below.

The frequency of hypovirus transmission into the conidia and ascospores was determined as follows. A portion of the conidial mass extruding from individual mature pycnidia was transferred with a sterile toothpick into a $1.5-\mathrm{ml}$ micro tube containing $50 \mu \mathrm{l}$ of sterile distilled water. After brief vortexing, $10 \mu \mathrm{l}$ of the conidial suspension was spread on $1.5 \%$ water agar and incubated in the dark at $25^{\circ} \mathrm{C}$ for 36 to $48 \mathrm{~h}$. Single germinating conidia were picked under a dissecting microscope and transferred onto potato dextrose agar (PDA, $39 \mathrm{~g} \mathrm{liters}^{-1}$; Difco Laboratories, Detroit). Single ascospore isolates were obtained as described by Rigling (36). Briefly, single perithecia were dissected from the stromata and crushed in a drop of water. The resulting ascospore suspensions were plated on $1.5 \%$ water agar and incubated at $25^{\circ} \mathrm{C}$ for 18 to $32 \mathrm{~h}$. When single germinating ascospores were observed under a dissecting microscope they were transferred to PDA.

The presence of the hypovirus $\mathrm{CHV}-1$ in each isolate was determined according to culture morphology on PDA $(7,17)$. Isolates were grown on PDA plates at $25^{\circ} \mathrm{C}$ in the dark for 7 days, followed by incubation under day light on the laboratory bench for 5 days. Isolates with yellow-orange pigmentation and abundant sporulation were considered to be hypovirus-free, whereas white isolates with sparse sporulation were classified as hypovirus-infected.
Statistical analysis. Statistical analysis of data was performed with the software program Systat, version 8.0 (Systat, Inc., Evanston, IL). The Wilcoxon signed rank test was used to compare the increments of canker length and stromata production between living and stacked stems. Chi-square tests were conducted to compare frequency of $C$. parasitica recovery and proportion of white isolates. Logistic regression and Scheffe post-hoc tests were used to test for differences among sites in the incidence of cankers yielding white isolates and the incidence of stems with stromata, as well as to compare the incidence of hypovirusinfected isolates recovered from different stromata types.

\section{RESULTS}

Growth and sporulation of $\boldsymbol{C}$. parasitica. Growth of $C$. parasitica between March 1996 and November 1996 was greater on the dead (i.e. cut and stacked) stems than on the living stems (Table 1). This difference was statistically significant $(P<0.05)$ for cankers that were originally inactive, which on average expanded by $8.2 \mathrm{~cm}$ on the dead stems, whereas they virtually did not grow on the living stems. The originally active cankers on average expanded by $8.3 \mathrm{~cm}$ on the dead stems compared to $4.8 \mathrm{~cm}$ on the living stems, but this difference was statistically not significant. In November 1996, 6 out of 25 stacked stems without cankers showed signs of $C$. parasitica colonization as indicated by the presence of typical yellowish to orange stromata. Average length of the newly colonized bark areas on these stems was $5.6 \mathrm{~cm}$. By contrast, none of the living stems without cankers showed signs of a $C$. parasitica infection, neither in November 1996 nor in April 1997.

Regardless of category of stems, $C$. parasitica produced significantly more stromata on the bark of dead chestnut stems than on living stems (Table 1). Active cankers already showed a substantial amount of stromata when the stems were cut in March 1996; by April 1997, stromata production had doubled on the dead stems, whereas it had decreased on the living stems. In March 1996, sporulation on inactive cankers was very rare; in November 1996 and April 1997 a significant $(P<0.05)$ increase in sporulation was observed on the dead stems whereas it remained low on the living stems. In both categories of cankers, stromata on the dead stems were observed on the surface of preexisting cankers as

TABLE 1. Canker development and stromata production by Cryphonectria parasitica on dead chestnut stems compared with living stems with or without canker

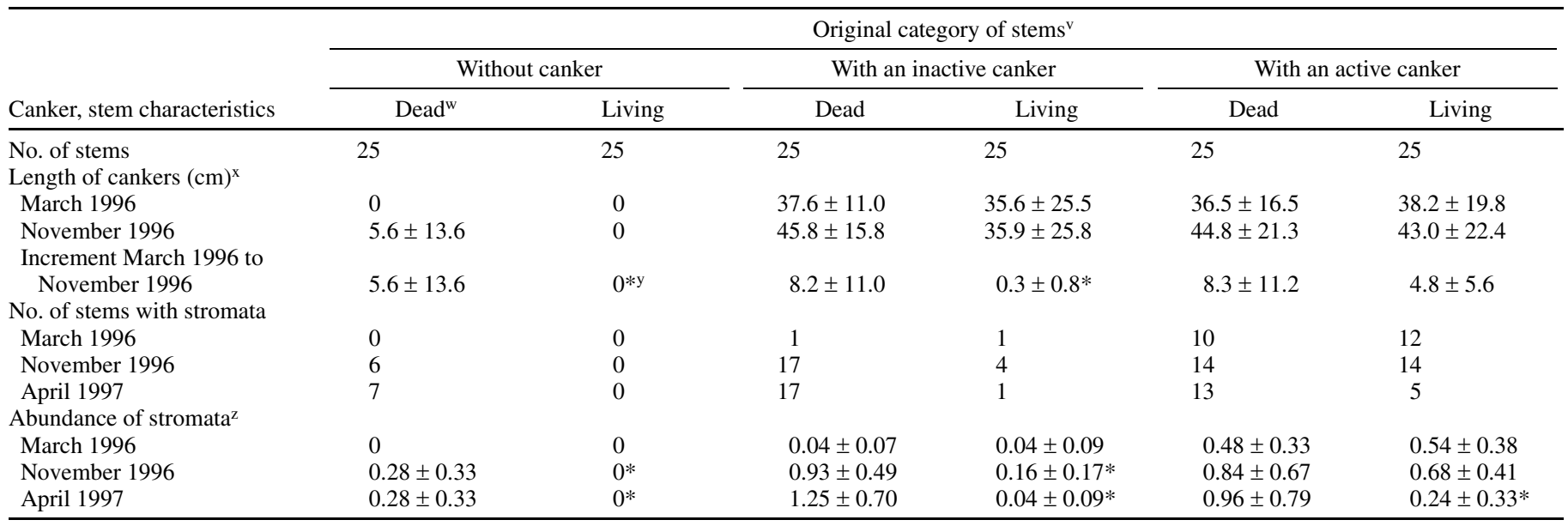

${ }^{v}$ Category of stems with active, inactive, or without cankers at the beginning of the experiment.

${ }^{w}$ Stems were cut and stacked in the forest in March 1996 at five sites.

${ }^{x}$ Canker lengths (mean \pm standard deviation). For the dead (cut and stacked) stems, length of the cankers in November 1996 equals the length of the initial cankers in March 1996 plus the length of the newly (saprophytically) colonized areas. For stacked stems without canker, the lengths of the newly (saprophytically) colonized areas are given.

y Values within a category of stems and a sampling date followed by an asterisk differ significantly $(P<0.05)$ between dead and living stems (increment of canker length, Wilcoxon signed rank test; stromata production, Mann-Whitney U-test).

${ }^{\mathrm{z}}$ Stromata production (mean estimate \pm standard deviation of the plot estimates) on the dead stems and on the living stems was determined using the scale $0=$ none, 1 = few, 2 = moderate, and $3=$ abundant. 
well as on newly colonized bark areas. When sporulation occurred on newly colonized areas, in $84 \%$ of the cases it was located adjacent to the preexisting cankers. At all three sampling dates, no significant differences in the incidence of dead stems with stromata were observed among the five sites (data not shown).

Survival of $C$. parasitica and incidence of white isolates. When the experiment commenced in March 1996, C. parasitica was recovered at high frequency from active and inactive cankers (Table 2). In November 1996 and April 1997 (i.e., 8 and 13 months later), the recovery of the pathogen remained high for both canker types on the dead stems. In contrast, on the living stems a significantly lower recovery rate was obtained from originally active cankers in April 1997 and from originally inactive cankers at both resampling dates. Dead stems originally without cankers also yielded more $C$. parasitica isolates than living stems but the overall frequency was low and the difference was only statistically significant in November 1996.

White isolates of $C$. parasitica (i.e., hypovirus-infected) were recovered from the cankers on the dead and living stems at all sites and sampling dates with an incidence ranging from 30.6 to $69.7 \%$ (Table 2). The incidence of cankers yielding at least one white isolate was higher (55.6 to $91.7 \%$ ) because five bark plugs were taken from each canker and several cankers yielded both white and orange isolates. From March 1996 to April 1997 no significant changes were observed in the percentage of hypovirusinfected cankers for stems with either canker type. However, the overall incidence of white isolates in originally inactive cankers increased from 41.4 to $69.7 \%$ on the dead stems, whereas it slightly decreased on the living stems (Table 2). Originally active cankers on both dead and living stems showed a slight increase in the incidence of white isolates over the observation period. Both in November 1996 and in April 1997, only a low percentage (27.3 and $12.5 \%$, respectively) of the isolates recovered from dead stems without cankers were hypovirus-infected. At all sampling dates, there were little differences among the five sites in the incidence of white isolates, with the exception of Copera that yielded significantly fewer white isolates than the other four sites (data not shown).

Characteristics of the stromata. In November 1996 and April 1997, a total of 37 stems that were cut and stacked in the forest showed stromata of $C$. parasitica on the bark (Table 3). The mean number of stromata per square centimeter of colonized bark was
12 in November 1996 and 11 in April 1997. At both sampling dates, the highest density of stromata was observed on the dead stems with an originally inactive canker. Bark samples with stromata were taken from the 37 stems and assessed for the presence of perithecia and pycnidia (i.e., mature pycnidia that released conidia upon wetting). Perithecia were found on all categories of stems, including those originally without cankers in March 1996. In total, the number of stems with perithecia was 18 in November 1997 and 25 in April 1997. Pycnidia were observed on 18 stems in November 1996 and on 20 stems in April 1997. Although the incidence of stems with perithecia and stems with pycnidia was similar, the proportion of perithecia and pycnidia differed considerably. With one exception (inactive cankers in November 1996), the proportion of stromata with perithecia was always higher than that of stromata with pycnidia, the latter never reaching more than $6 \%$. In all categories of stems, however, the majority of individual stromata (mean of $76.3 \%$ in November 1996 and of $70.9 \%$ in April 1997) contained neither perithecia nor pycnidia and were consequently classified as nondifferentiated. In all five plots, there were little differences between bark samples from preexisting cankers and from newly colonized bark areas in the incidence of the three types of stromata (data not shown).

A total of $56 \%$ of the bark samples in November 1996 and of $35 \%$ in April 1997 showed only nondifferentiated stromata (data not shown). On the other bark samples, nondifferentiated stromata were commonly observed beside stromata with perithecia and/or pycnidia. About 5\% of the bark samples in November 1996 and 9\% in April 1997 contained both perithecia and pycnidia. The incidence of white isolates varied greatly among the different stromata types (Table 4). On average, stromata with perithecia yielded the lowest proportion of white isolates at both sampling dates, followed by stromata with pycnidia and by nondifferentiated stromata.

Since the incidence of white isolates in the cankers at the time of sprout cutting (March 1996) is known, we were able to assess the effect of the hypovirus on the sporulation of $C$. parasitica on the stacked stems (Fig. 2). The majority of the cankers that were hypovirus-infected in March 1996 produced no or only nondifferentiated stromata in November 1996. In contrast, perithecia preferentially developed on formerly hypovirus-free cankers.

Comparison of experimental stacks and other types of dead wood. To gain a more general view of the sporulation of $C$. para-

TABLE 2. Recovery of Cryphonectria parasitica and proportion of white (hypovirus-infected) isolates on dead chestnut stems compared with living stems with or without canker

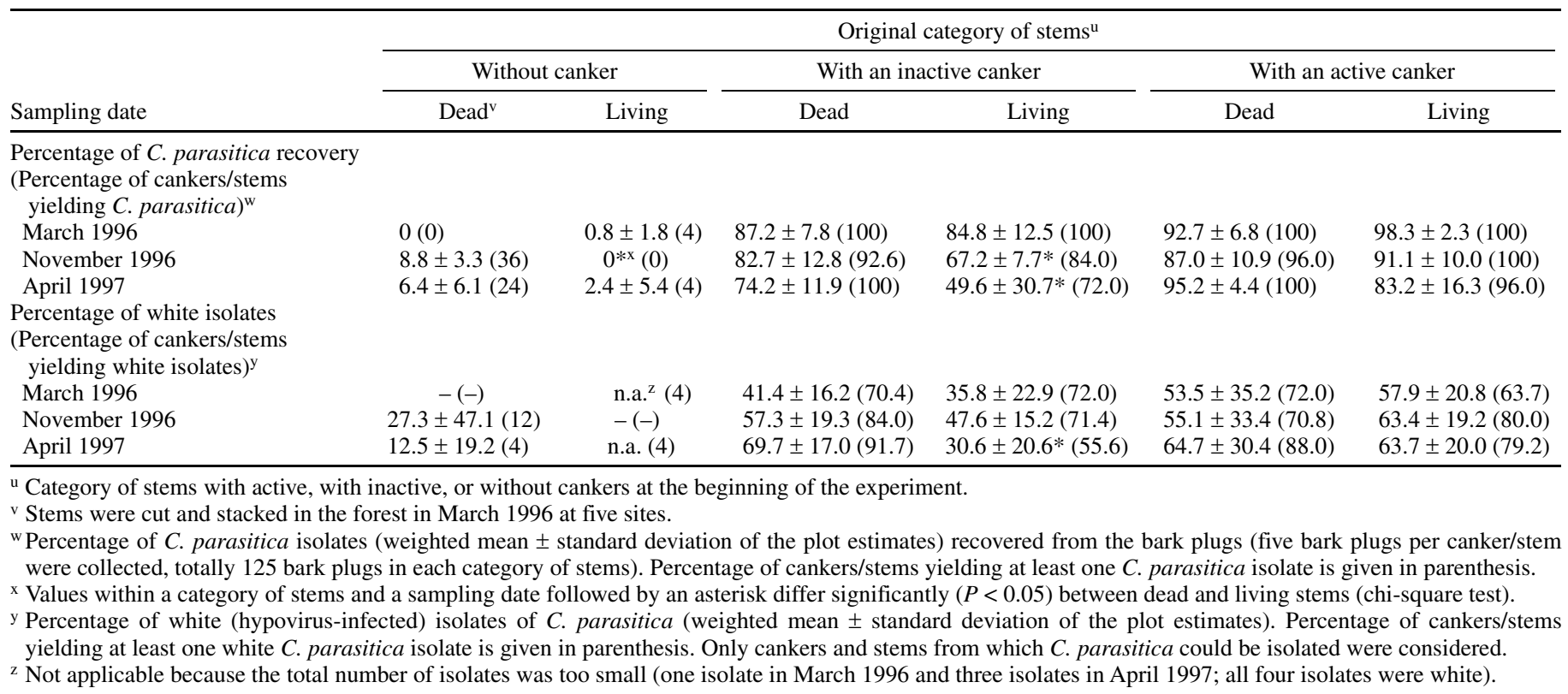


sitica on dead chestnut wood, we compared our experimental stacks with stems that died naturally and with stems that were cut and stacked by forest owners for the use as firewood (Fig. 3). All three types of stromata (i.e., with perithecia, with pycnidia, and nondifferentiated) observed on the experimental stacks also were found on natural dead wood and on firewood stacks (Fig. 3A). The proportion of stromata with perithecia on the firewood stacks and on natural dead wood (62.7 and $57.9 \%$, respectively) was higher than on the experimental stacks. In contrast, nondifferentiated stromata were more frequent on the experimental stacks. As for the experimental stacks, the proportion of stromata with pycnidia on the two other types of dead wood was low $(<7 \%$ of the stromata). The incidence of white $C$. parasitica isolates recovered from stromatal tissue varied greatly among types of dead wood and types of stromata (Fig. 3B). Unlike the experimental stacks, no significant differences in the proportion of white isolates were observed among stromata types on the firewood stacks and on the natural dead wood. The latter showed a very low proportion of white isolates for all stromata types probably because of frequent infections by virus-free ascospores.

Vertical transmission of hypoviruses. A total of 59 pycnidia from 35 bark samples collected from the experimental stacks in
November 1996 and in April 1997 were randomly selected and investigated for transmission of the hypovirus into the conidia (Table 4). Thirty of these pycnidia yielded an orange (hypovirusfree) and 29 yielded a white (hypovirus-infected) stromatal isolate. All pycnidia from hypovirus-infected stromatal tissue yielded some white single conidial isolates. The mean percent of white isolates among conidia in these pycnidia was $69 \%$ (4 to 100\%). In contrast, no white isolates were obtained from conidia produced by pycnidia from hypovirus-free stromatal tissue. Since we occasionally recovered white isolates from stromatal tissue that contained perithecia (Table 4, Fig. 3), we also tested for transmission of the hypovirus into ascospores. None of the isolates derived from single ascospores were white whether or not the stromatal tissue was hypovirus-infected (Table 5). This confirms that the hypovirus is not transmitted into ascospores $(3,10)$.

\section{DISCUSSION}

We observed a considerable saprophytic activity and sporulation of $C$. parasitica on the bark of recently dead chestnut wood. After cutting of chestnut trees the pathogen readily survived in cankers for more than 1 year. In originally inactive cankers, the

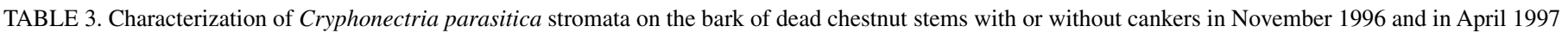

\begin{tabular}{|c|c|c|c|c|c|c|c|c|}
\hline \multirow[b]{2}{*}{$\begin{array}{l}\text { Original category } \\
\text { of stems }{ }^{\mathrm{u}}\end{array}$} & \multirow[b]{2}{*}{$\begin{array}{c}\text { No. of bark } \\
\text { samples analyzed }^{v}\end{array}$} & \multicolumn{3}{|c|}{ No. of stems (sites) with stromataw } & \multicolumn{3}{|c|}{ Proportion of stromata type $(\%)^{\mathrm{x}}$} & \multirow{2}{*}{$\begin{array}{c}\text { Density of } \\
\text { stromata } \\
\left(\mathrm{cm}^{-2}\right)^{\mathrm{y}}\end{array}$} \\
\hline & & Total & $\begin{array}{l}\text { With } \\
\text { perithecia }\end{array}$ & $\begin{array}{c}\text { With } \\
\text { pycnidia }\end{array}$ & $\begin{array}{c}\text { With } \\
\text { perithecia }\end{array}$ & $\begin{array}{c}\text { With } \\
\text { pycnidia }\end{array}$ & $\begin{array}{c}\text { Non- } \\
\text { differentiated }\end{array}$ & \\
\hline \multicolumn{9}{|l|}{ November 1996} \\
\hline With an active canker & 44 & $14(4)$ & $7(3)$ & $6(3)$ & $33.7 \pm 33.5$ & $2.5 \pm 1.6$ & $63.8 \pm 34.2$ & $11.2 \pm 7.3$ \\
\hline With an inactive canker & 58 & $17(5)$ & $6(4)$ & $11(4)$ & $2.9 \pm 6.7$ & $5.8 \pm 4.7$ & $91.4 \pm 5.0$ & $12.9 \pm 5.1$ \\
\hline Without canker & 13 & $6(3)$ & $5(3)$ & $1(1)$ & $39.2 \pm 27.9$ & $0.7 \pm 3.5$ & $60.1 \pm 30.6$ & $11.5 \pm 5.8$ \\
\hline Total, mean ${ }^{z}$ & 115 & $37(5)$ & $18(5)$ & $18(4)$ & $19.9 \pm 24.7$ & $3.8 \pm 3.9$ & $76.3 \pm 24.6$ & $12.0 \pm 5.6$ \\
\hline \multicolumn{9}{|l|}{ April 1997} \\
\hline With an active canker & 38 & $13(4)$ & $7(3)$ & $8(4)$ & $41.1 \pm 38.0$ & $3.1 \pm 1.6$ & $55.8 \pm 36.7$ & $10.0 \pm 6.1$ \\
\hline With an inactive canker & 54 & $17(5)$ & $13(5)$ & $8(4)$ & $11.9 \pm 4.3$ & $2.7 \pm 3.5$ & $85.4 \pm 6.2$ & $13.6 \pm 4.2$ \\
\hline Without canker & 14 & $7(3)$ & $5(3)$ & $4(2)$ & $42.4 \pm 6.4$ & $2.1 \pm 1.9$ & $55.5 \pm 8.2$ & $8.3 \pm 4.0$ \\
\hline Total, mean & 106 & $37(5)$ & $25(5)$ & $20(5)$ & $26.4 \pm 23.7$ & $2.7 \pm 2.5$ & $70.9 \pm 23.2$ & $11.1 \pm 5.1$ \\
\hline
\end{tabular}

u Stems originally with active, with inactive, or without cankers were cut and stacked in the forest in March 1996.

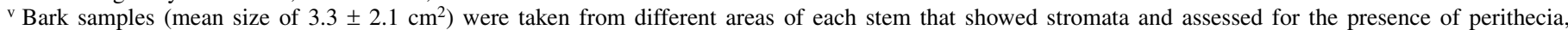
pycnidia, and nondifferentiated stromata.

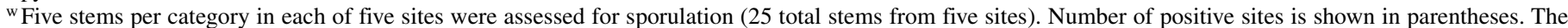
totals also include stems with only nondifferentiated stromata. Seven stems in November 1996 and nine stems in April 1997 showed neither pycnidia nor perithecia (i.e., only nondifferentiated stromata were observed), whereas nine stems in November 1996 and 14 stems in April 1997 had both pycnidia and perithecia.

$\mathrm{x}$ Weighted mean \pm standard deviation of the plot estimates.

y Density of stromata (mean \pm standard deviation) on the bark samples.

z Total number of stems with stromata and number of bark samples; mean percentage of stromata type and density of stromata.

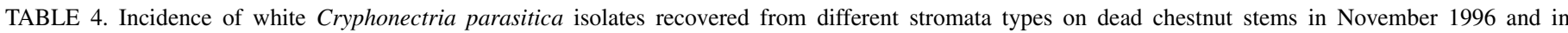
April 1997

\begin{tabular}{|c|c|c|c|c|c|c|c|c|}
\hline \multirow{3}{*}{$\begin{array}{l}\text { Original category } \\
\text { of stems }\end{array}$} & \multicolumn{8}{|c|}{ Stromata type } \\
\hline & \multicolumn{2}{|c|}{ All } & \multicolumn{2}{|c|}{ With perithecia } & \multicolumn{2}{|c|}{ With pycnidia } & \multicolumn{2}{|c|}{ Nondifferentiated } \\
\hline & No. of isolates ${ }^{w}$ & $\%$ White & No. of isolates & $\%$ White & No. of isolates & $\%$ White & No. of isolates & $\%$ White \\
\hline \multicolumn{9}{|l|}{ November 1996} \\
\hline With an active canker & 262 & $37.8 \pm 39.8^{x}$ & 72 & 0 & 29 & $20.7 \pm 28.9$ & 161 & $57.8 \pm 43.9$ \\
\hline With an inactive canker & 342 & $53.5 \pm 36.1$ & 19 & $5.3 \pm 50.0$ & 50 & $58.0 \pm 50.8$ & 273 & $56.0 \pm 34.1$ \\
\hline Without canker & 84 & $23.8 \pm 25.1$ & 32 & $12.5 \pm 14.4$ & 6 & 0 & 46 & $34.8 \pm 37.0$ \\
\hline Total, mean ${ }^{y}$ & 688 & $43.9 \pm 36.1$ & 123 & $4.1 \pm 33.3 \mathrm{a}^{\mathrm{z}}$ & 85 & $41.2 \pm 42.9 \mathrm{~b}$ & 480 & $54.6 \pm 38.2 \mathrm{~b}$ \\
\hline \multicolumn{9}{|l|}{ April 1997} \\
\hline With an active canker & 239 & $45.2 \pm 41.6$ & 79 & 0 & 28 & $39.3 \pm 34.6$ & 132 & $73.5 \pm 42.6$ \\
\hline With an inactive canker & 364 & $46.2 \pm 23.8$ & 73 & $28.8 \pm 35.7$ & 33 & $30.3 \pm 41.2$ & 258 & $53.1 \pm 23.9$ \\
\hline Without canker & 111 & $24.3 \pm 27.3$ & 54 & $16.7 \pm 19.2$ & 8 & $50.0 \pm 40.4$ & 49 & $28.6 \pm 32.3$ \\
\hline Total, mean & 714 & $42.4 \pm 33.7$ & 206 & $14.6 \pm 26.6 \mathrm{a}$ & 69 & $36.2 \pm 38.5 b$ & 439 & $56.5 \pm 36.4 \mathrm{c}$ \\
\hline
\end{tabular}

${ }^{\mathrm{w}}$ One isolate per individual stroma was recovered.

${ }^{x}$ Weighted mean \pm standard deviation of the plot estimates.

y Total number of isolates; mean percentage of white isolates.

$\mathrm{z}$ Values within a row followed by different letters differ significantly (logistic regression, $P<0.05$ ). 


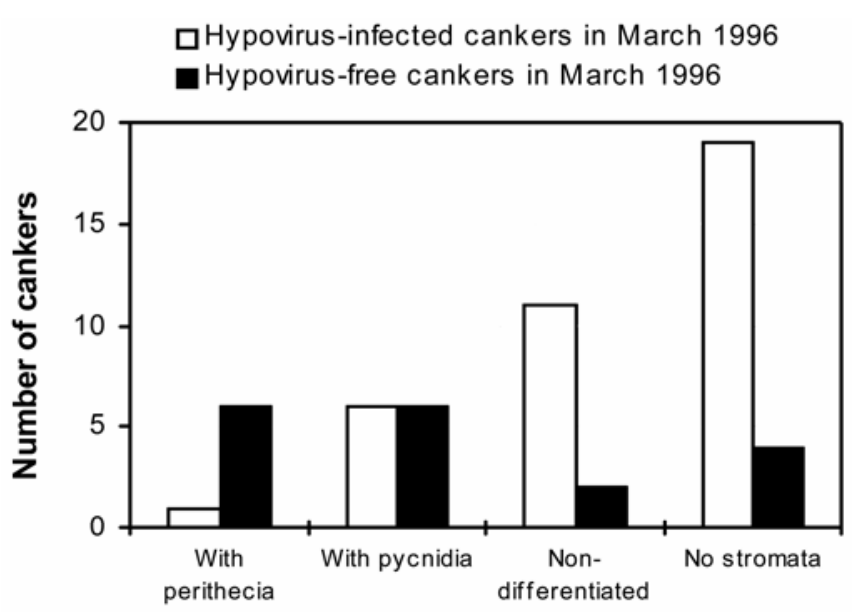

Type of stromata in Nov 1996

Fig. 2. Relationship between presence of hypovirus in the cankers on the stacked stems in March 1996 (time of sprout cutting) and the type of Cryphonectria parasitica stromata observed on the surface of these cankers in November 1996. Nondifferentiated stromata contained neither perithecia nor pycnidia.

fungus resumed growth resulting in colonization of new bark areas adjacent to the cankers and stromata production. In addition, several stacked stems showed newly colonized bark areas with stromata not associated with the original cankers. In contrast, no resumed growth of inactive cankers or new infections was detected on the living trees during the observation period. These results suggest that in our study area $C$. parasitica is more likely to colonize the bark of dead chestnut wood than cause new infections on living trees. As a necrotrophic bark pathogen, C. parasitica probably exploits the weakened host defense mechanisms as well as the favorable conditions of the moribund bark substrate after trees are cut. Gao and Shain (18) showed that a decreasing relative turgidity in the bark promoted canker expansion on dormant excised chestnut stems. Water stress could have the same growth promoting effect on the colonization of uninfected bark areas by $C$. parasitica.

The expansion of cankers on the stacked stems has probably occurred through outgrowth of the canker infection. Newly colonized bark not in contact with cankers or on stems without cankers could have been incited either by spores that newly arrive or are already present on the bark surface at the time of cutting or by endophytic mycelium (i.e., latent infections) of $C$. parasitica $(8,22,40)$. In accordance with these reports, in a few cases we recovered $C$. parasitica from the bark of apparently healthy living sprouts.

The role of dead chestnut wood in the epidemiology of hypovirulence is not easy to assess from our results. Clearly, sporulation (i.e., incidence of stromata) on the bark of dead wood was significantly more abundant than on the living sprouts. This difference was particularly evident for inactive cankers, which showed a considerable sporulation only on the stacked stems. Both hypovirus-free and hypovirus-infected strains of $C$. parasitica were able to survive and sporulate on dead wood. The consistently greater abundance of perithecia compared to pycnidia on all types of dead wood points to an advantage for the virulent form of the pathogen. First, perithecia only produce hypovirusfree ascospores, which are dispersed over longer distances than conidia (23). Second, sexual reproduction can maintain or increase vc type diversity, thereby negatively affecting the spread of hypoviruses within populations $(13,29)$. However, in our study the abundance of perithecia might have been partially overestimated because of the impossibility to distinguish mature and empty perithecia without microscopic examinations. Thus, the propor-
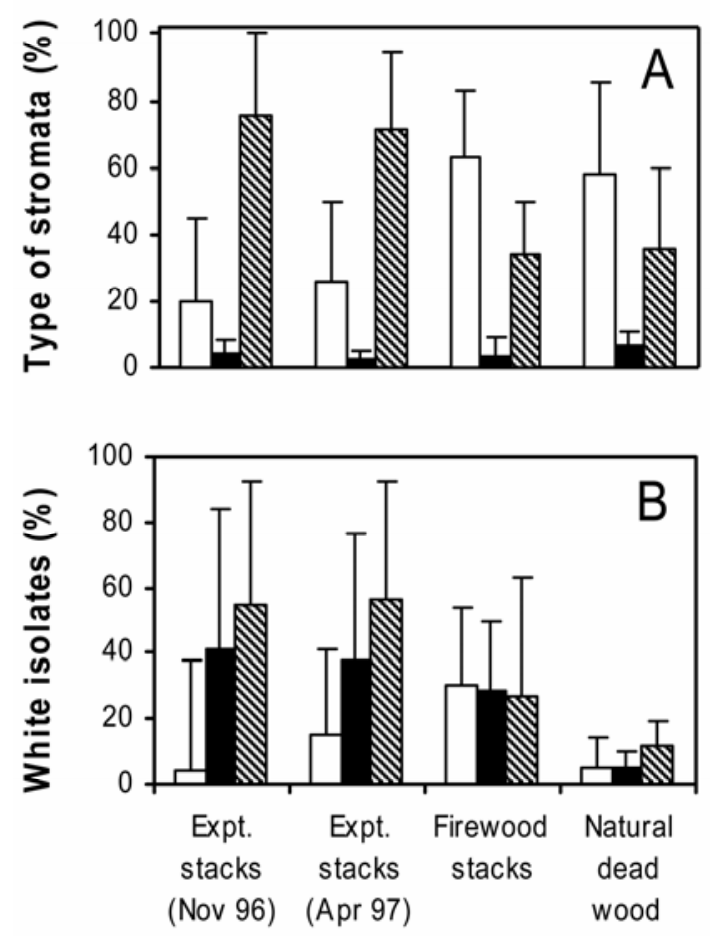

\section{Type of dead wood}

Fig. 3. Characteristics of Cryphonectria parasitica sporulation on the stems that were experimentally cut and stacked, compared with stems that died naturally and with stems cut and stacked for firewood. A, Proportion of stromata with perithecia, with pycnidia, and without differentiated fruiting bodies (i.e., neither perithecia nor pycnidia were observed). B, Incidence of white C. parasitica isolates recovered from the different stromata types. Error bars represent standard deviations of the plot estimates.

tions of stromata with perithecia represent cumulative values of the perithecia formed on dead wood. In contrast, the overall abundance of pycnidia on dead wood may have been underestimated. Pycnidia were considered to be present if they were mature, i.e., released conidia upon wetting. It is possible that many stromata recorded as nondifferentiated contained immature or empty pycnidia.

Our results indicate that recently dead wood can act as a reservoir of hypovirulent inoculum. The incidence of hypovirusinfected isolates increased on the cut stems probably because of both movement of hypovirus in already infected cankers and new viral infections of formerly hypovirus-free cankers. Depending on the type of dead wood, between 5 and $41 \%$ (mean 26\%) of the stromata with pycnidia were hypovirus-infected. All pycnidia examined from these stromata produced hypovirus-infected conidia with a mean frequency of hypovirus transmission into the conidia of $69 \%$. Based on this transmission rate, we estimate that between 3.4 and $28.1 \%$ (mean $18 \%$ ) of all the conidia produced on various types of dead wood were hypovirus-infected. Considering the infectious nature of hypovirulence, these percentages of hypovirus-infected conidia might be relevant for the dissemination of the hypovirus within a forest stand, particularly when conidia are transported by various vectors $(16,32,42,45)$. If vectored by fungus-feeding insects such as mites $(32,48)$, then stromatal tissue itself, with or without differentiated fruiting bodies, could play a role in the spread of the hypovirus. More research is required to 
TABLE 5. Hypovirus transmission (\% white isolates) into asexual and sexual spores of Cryphonectria parasitica produced on dead chestnut wood

\begin{tabular}{|c|c|c|c|c|c|c|}
\hline \multirow[b]{3}{*}{ Stromatal isolate $^{\mathrm{x}}$} & \multicolumn{3}{|c|}{ Asexual spores } & \multicolumn{3}{|c|}{ Sexual spores } \\
\hline & \multirow[b]{2}{*}{ No. of pycnidia } & \multicolumn{2}{|c|}{ Single conidial isolates } & \multirow[b]{2}{*}{ No. of perithecia } & \multicolumn{2}{|c|}{ Single ascospore isolates } \\
\hline & & $\mathrm{N}$ & $\%$ White & & $\mathrm{N}$ & $\%$ White \\
\hline Orange (hypovirus-free) & 30 & 802 & 0 & 12 & 286 & 0 \\
\hline White (hypovirus-infected) & 29 & 770 & $69^{y}$ & 10 & 257 & 0 \\
\hline Total, mean ${ }^{z}$ & 59 & 1,572 & 34 & 22 & 543 & 0 \\
\hline
\end{tabular}

x Culture morphology of isolates recovered from stromata with pycnidia or perithecia.

y The standard deviation of the 29 pycnidial estimates was 28 .

$\mathrm{z}$ Total number of pycnidia/perithecia and isolates; mean proportion of white isolates.

clarify the role of conidia and stromatal hyphae and their possible vectors for the dissemination of the hypovirus.

Hypovirulence is widespread in our study area $(7,11)$ and, as anticipated from other in vitro and in vivo studies $(17,34,49)$, it has subsequently affected the type of sporulation on dead wood. There was less sporulation and a dominance of nondifferentiated stromata on the cankers that were hypovirus-infected at the time of cutting. Likewise, white isolates were more frequently recovered from nondifferentiated stromata than from stromata with pycnidia or perithecia. In addition, when a low incidence of white isolates was observed (e.g., on the colonized natural dead wood) many perithecia were produced. Presumably, in regions with no or a low incidence of hypovirulence (e.g., in North America), sporulation on dead wood is likely more abundant with a higher incidence of perithecia and/or pycnidia.

In the chestnut forests in southern Switzerland, dead wood is common, either because stands have been abandoned or as a consequence of management interventions (thinning, timber harvesting, and firewood management in coppice forests; pruning in orchards). According to the last National Forest Inventory (1993 to 1995), the amount of dead chestnut wood (considered as volume of stems with diameter at breast height $\geq 12 \mathrm{~cm}$ ) represents on average $5 \%$ of the standing volume, i.e., about 5 to $10 \mathrm{~m}^{3}$ $\mathrm{ha}^{-1}$ of dead wood (9). In old abandoned chestnut coppices, the volume of dead chestnut sprouts ( $>8 \mathrm{~cm}$ in diameter) may reach 10 to $28 \%$ (19, F. Giudici and A. Zingg, personal communication) and most sprout mortality has been attributed to competition within sprout clusters (7). Our findings indicate that dead chestnut wood supports the saprophytic activity of $C$. parasitica for at least 1 or 2 years after death of the stems. The frequent occurrence of dead chestnut wood in southern Switzerland combined with the saprophytic activity of $C$. parasitica we report suggests that recently dead wood can contribute to the observed biological control of chestnut blight in this region. Recently dead chestnut wood probably also contributes to the dissemination of the hypovirus in other European populations of $C$. parasitica where hypovirulence is now widespread (e.g., Italy and regions of France).

As our study shows, the hypovirus survives and spreads in preexisting cankers on recently dead chestnut wood. In addition, the bark of dead wood is a favorable substrate for saprophytic colonization and asexual sporulation of hypovirus-infected strains. In contrast, on living trees sporulation is rare and generally limited to hypovirus-free strains $(17,34)$. The numerous inactive cankers observed on living trees may represent a kind of latent stage in the epidemiology of the hypovirus until the trees die, either naturally or after management interventions, allowing the hypovirus-infected canker isolate to grow saprophytically and produce hypovirus-infected conidia. Therapeutic treatments of individual cankers, although mostly successful in controlling canker expansion, may also only little contribute to the spread of the hypovirus. The saprophytic activity of hypovirus-infected $C$. parasitica strains has the potential to improve biological control of chestnut blight, particularly in areas where control efforts have failed because of limited dissemination of the hypovirus (30). For example, traditional canker treatments could be accompanied by depositing segments of chestnut wood inoculated with hypovirusinfected $C$. parasitica strains in the stands. In addition, a certain number of stems with inactive cankers could periodically be cut and stacked to allow sporulation of hypovirus-infected $C$. parasitica strains. The same approach would theoretically apply for stems with active cankers after canker treatment and conversion. However, additional experimental evidence is needed to establish the epidemiological relationship between the occurrence of the saprophytic activity of hypovirus-infected $C$. parasitica and the success of hypovirulence.

\section{ACKNOWLEDGMENTS}

We thank P. Roth for assistance in the field and P. Reeser for the English revision of the manuscript. We also thank two anonymous reviewers for valuable comments on the manuscript.

\section{LITERATURE CITED}

1. Allemann, C., Hoegger, P., Heiniger, U., and Rigling, D. 1999. Genetic variation of Cryphonectria hypoviruses (CHV1) in Europe assessed using restriction fragment length polymorphism (RFLP) markers. Mol. Ecol. 8:843-854

2. Anagnostakis, S. L. 1987. Chestnut blight: The classical problem of an introduced pathogen. Mycologia 79:23-37.

3. Anagnostakis, S. L. 1988. Cryphonectria parasitica, cause of chestnut blight. Adv. Plant Pathol. 6:123-136.

4. Anagnostakis, S. L., and Day, P. R. 1979. Hypovirulence conversion in Endothia parasitica. Phytopathology 69:1226-1229.

5. Anagnostakis, S. L., Hau, B., and Kranz, J. 1986. Diversity of vegetative compatibility groups of Cryphonectria parasitica in Connecticut and Europe. Plant Dis. 70:536-538.

6. Baird, R. E. 1991. Growth and stromata production of hypovirulent and virulent strains of Cryphonectria parasitica on dead Quercus rubra and Acer rubrum. Mycologia 83:158-162.

7. Bissegger, M., Rigling, D., and Heiniger, U. 1997. Population structure and disease development of Cryphonectria parasitica in European chestnut forests in the presence of natural hypovirulence. Phytopathology 87:50-59.

8. Bissegger, M., and Sieber, T. N. 1994. Assemblages of endophytic fungi in coppice shoots of Castanea sativa. Mycologia 86:648-665.

9. Brändli, U.-B., and Ulmer, U. 1999. Protezione della natura e ricreazione. Pages 279-329 in: Inventario Forestale svizzero. Risultati del secondo inventario 1993-1995. P. Brassel and U.-B. Brändli, eds, Birmensdorf, Istituto federale di ricerca per la foresta, la neve e il paesaggio; Berna, Ufficio federale dell'ambiente, delle Foreste e del Paesaggio. Haupt, Berna, Stoccarda, Vienna.

10. Carbone, I., Liu, Y.-C., Hilmann, B. I., and Milgroom, M. G. 2004. Recombination and migration of Cryphonectria hypovirus 1 as inferred from gene genealogies and the coalescent. Genetics 166:1611-1629.

11. Conedera, M. 1991. La situazione del cancro corticale del castagno (Cryphonectria [Endothia] parasitica [Murr.] And.) al Sud delle Alpi (Svizzera meridionale). Schweiz. Z. Forstwes. 142:283-298.

12. Conedera, M. 1993. Cancro corticale del castagno: principali caratteristiche epidemiologiche e misure pratiche di controllo. Ber. Eidgenöss. Forsch.anst. Wald Schnee Landsch., Birmensdorf. No. 335.

13. Cortesi, P., McCulloch, C. E., Song, H., Lin, H., and Milgroom, M. G. 2001. Genetic control of horizontal virus transmission in the chestnut blight fungus, Cryphonectria parasitica. Genetics 159:107-118.

14. Cortesi, P., and Milgroom, M. G. 1998. Genetics of vegetative incompatibility in Cryphonectria parasitica. Appl. Environ. Microbiol. 64:29882994. 
15. Cortesi, P., Milgroom, M. G., and Bisiach, M. 1996. Distribution and diversity of vegetative compatibility in subpopulations of Cryphonectria parasitica in Italy. Mycol. Res. 100:1087-1093.

16. Elliston, J. E. 1982. Hypovirulence. Adv. Plant Pathol. 1:1-33.

17. Elliston, J. E. 1985. Characteristics of dsRNA-free and dsRNA-containing strains of Endothia parasitica in relation to hypovirulence. Phytopathology 75:151-158.

18. Gao, S., and Shain, L. 1995. Effects of water stress on chestnut blight. Can. J. For. Res. 25:1030-1035.

19. Giudici, F., and Zingg, A. 2005. Sprouting ability and mortality of chestnut (Castanea sativa Mill.) after coppicing. A case study. Ann. For. Sci. 62:513-523.

20. Gobbin, D., Hoegger, P. J., Heiniger, U., and Rigling, D. 2003. Sequence variation and evolution of Cryphonectria hypoviruses (CHV-1) in Europe. Virus Res. 97:39-46.

21. Griffin, G. J. 1986. Chestnut blight and its control. Hort. Rev. 8:291-336.

22. Guerin, L., and Robin, C. 2003. Seasonal effect on infection and development of lesions caused by Cryphonectria parasitica in Castanea sativa. For. Pathol. 33:223-235.

23. Heald, F. D., Gardner, M. W., and Studhalter, R. A. 1915. Air and wind dissemination of ascospores of the chestnut blight fungus. J. Agric. Res. 3:493-526.

24. Heiniger, U., and Rigling, D. 1994. Biological control of chestnut blight in Europe. Annu. Rev. Phytopathol. 32:581-599.

25. Hillman, B. I., Fulbright, D. W., Nuss, D. L., and Van Alfen, N. K. 2000. Hypoviridae in Virus Taxonomy. Pages 515-520 in: Seventh Report of the International Committee for the Taxonomy of Viruses. M. H. V. van Regenmortel, C. M. Fauquet, D. H. L. Bishop, E. B. Carstens, M. K. Estes, S. M. Lemon, J. Maniloff, M. A. Mayo, D. J. McGeoch, C. R. Pringle, and R. B. Wickner, eds. Academic Press, San Diego, CA.

26. Hoegger, P. J., Heiniger, U., Holdenrieder, O., and Rigling, D. 2003. Differential transfer and dissemination of the hypovirus and the nuclear and mitochondrial genomes of a hypovirus-infected Cryphonectria parasitica strain after its introduction into a natural population. Appl. Environ. Microbiol. 69:3767-3771.

27. Hoegger, P. J., Rigling, D., Holdenrieder, O., and Heiniger, U. 2000. Genetic structure of newly established populations of Cryphonectria parasitica. Mycol. Res. 104:1108-1116.

28. MacDonald, W. L., and Fulbright, D. W. 1991. Biological control of chestnut blight: Use and limitations of transmissible hypovirulence. Plant Dis. 75:656-661.

29. Milgroom, M. G., and Cortesi, P. 1999. Analysis of population structure of the chestnut blight fungus based on vegetative incompatibility genotypes. Proc. Natl. Acad. Sci. USA 96:10518-10523.

30. Milgroom, M. G., and Cortesi, P. 2004. Biological control of chestnut blight with hypovirulence: A critical analysis. Annu. Rev. Phytopathol. 42:311-338.

31. Mittempergher, L. 1982. The present status of chestnut blight in Italy. Pages 34-37 in: Proc. Am. Chestnut Symp. W. L. MacDonald, F. C. Cech, J. Luchok, and C. Smith, eds. W. Va. Univ. Books, Morgantown.

32. Nannelli, R., Turchetti, T., and Maresi, G. 1998. Corticolous mites (Acari) as potential vectors of Cryphonectria parasitica (Murr.) Barr hypovirulent strains. Int. J. Acarol. 24:237-244.

33. Nuss, D. L. 2000. Hypovirulence and chestnut blight: from the field to the laboratory and back. Pages 149-170 in: Fungal Pathology. J. W. Kronstad, ed. Kluwer Academic Publishers, Dordrecht, the Netherlands.

34. Peever, T. L., Liu, Y.-C., Cortesi, P., and Milgroom, M. G. 2000. Variation in tolerance and virulence in the chestnut blight fungus-hypovirus interaction. Appl. Environ. Microbiol. 66:4863-4869.

35. Prospero, S., Conedera, M., Heiniger, U., and Rigling, D. 1998. Sopravvivenza e sporulazione di Cryphonectria parasitica su legna di Castanea sativa depositata in bosco. Monti Boschi 3/4:44-50.

36. Rigling, D. 1995. Isolation and characterization of Cryphonectria parasitica mutants that mimic a specific effect of hypovirulence-associated dsRNA on laccase activity. Can. J. Bot. 73:1655-1661.

37. Rigling, D., Heiniger, U., and Hohl, H. R. 1989. Reduction of laccase activity in dsRNA-containing hypovirulent strains of Cryphonectria (Endothia) parasitica. Phytopathology 79:219-223.

38. Robin, C., Anziani, C., and Cortesi, P. 2000. Relationship between biological control, incidence of hypovirulence, and diversity of vegetative compatibility types of Cryphonectria parasitica in France. Phytopathology 90:730-737.

39. Robin, C., and Heiniger, U. 2001. Chestnut blight in Europe: Diversity of Cryphonectria parasitica, hypovirulence, and biocontrol. For. Snow Lands. Res. 76:361-367.

40. Russin, J. S., and Shain, L. 1984. Initiation and development of cankers caused by virulent and cytoplasmatic hypovirulent isolates of the chestnut blight fungus. Can. J. Bot. 62:2660-2664.

41. Russin, J. S., and Shain, L. 1985. Disseminative fitness of Endothia parasitica containing different agents for cytoplasmatic hypovirulence. Can. J. Bot. 63:54-57.

42. Russin, J. S., Shain, L., and Nordin, G. L. 1984. Insects as carriers of virulent and cytoplasmatic hypovirulent isolates of the chestnut blight fungus. J. Econ. Entomol. 77:838-846.

43. Sotirovski, K., Milgroom, M. G., Rigling, D., and Heiniger, U. 2006. Occurrence of Cryphonectria hypovirus 1 in the chestnut blight fungus in Macedonia. For. Pathol. 36:136-143.

44. Spinedi, F., and Isotta, F. 2004. Il clima in Ticino. Dati, statistica e società 4:5-39.

45. Turchetti, T., and Chelazzi, G. 1984. Possible role of slugs as vectors of the chestnut blight fungus. Eur. J. For. Pathol. 14:125-127.

46. Van Alfen, N. K. 1982. Biology and potential for disease control of hypovirulence of Endothia parasitica. Annu. Rev. Phytopathol. 20:349-362.

47. Van Alfen, N. K., Jaynes, R. A., Anagnostakis, S. L., and Day, P. R. 1975. Chestnut blight: Biological control by transmissible hypovirulence in Endothia parasitica. Science 189:890-891.

48. Wendt, R., Weidhass, J., Griffin, G. J., and Elkins, J. R. 1983. Association of Endothia parasitica with mites isolated from cankers on American chestnut trees. Plant Dis. 67:757-758.

49. Zhang, L., Baasiri, R. A., and Van Alfen, N. K. 1998. Viral suppression of fungal pheromone precursor gene expression. Mol. Cell. Biol. 18:953959. 